\title{
Modelo computacional de redução de custos em redes coletoras de esgoto sanitário com a utilização de um algoritmo híbrido de busca exaustiva em largura
}

\author{
Computational model of cost reduction in sanitary sewage systems with \\ the use of a hybrid algorithm of width exhaustive search
}

\section{Gustavo Paiva Weyne Rodrigues | Luis Henrique Magalhães Costa | Marco Aurélio Holanda de Castro}

Data de entrada: 09/04/2011 | Data de aprovação:11/06/2012

Resumo

O Brasil está aquém do nível satisfatório no que concerne aos sistemas de esgotamento sanitário. O cálculo manual de quantitativos em redes de abastecimento de água e esgotamento sanitário é lento e, muitas vezes, de precisão duvidosa, devido às quantidades que são estimadas ou arbitradas em vários itens pertencentes ao orçamento. Foi desenvolvido um modelo computacional para redução de custos em redes coletoras de esgoto sanitário, de forma a garantir o adequado comportamento hidráulicosanitário. A metodologia proposta foi avaliada por meio de dois estudos de casos reais. Os resultados obtidos nos estudos de casos demonstram a aplicabilidade do modelo em escala real, pois a ferramenta computacional reduziu os custos em todos os casos, o que possibilita a utilização em projetos de uma forma simples e intuitiva.

Palavras-chave: sistemas de esgotos sanitários, custos em redes de esgotos, algoritmos de busca, busca exaustiva

\begin{abstract}
Brazil is far from being satisfactory with regard to sewerage services. Manual calculation of quantitative nets from water supply and sewage systems is slow and often leads to dubious accuracy due to quantities that are estimated or arbitrated. A computational model for cost reduction in sanitary sewage systems was developed in order to ensure adequate health-hydraulic behavior. The proposed methodology was evaluated through two real case studies. The obtained results in demonstrate model ' $s$ applicability, allowing its use in designing in a simple and intuitive way.
\end{abstract}

Key-words: sanitary sewage systems, sewage net costs, search algorithms, exhaustive search

Gustavo Paiva Weyne Rodrigues*

Engenheiro Civil. Doutor em Saneamento Ambiental pela Universidade Federal do Ceará. Consultor em projetos de saneamento ambiental.

Luis Henrique Magalhães Costa

Engenheiro Civil. Doutor em Recursos Hídricos pela Universidade Federal do Ceará. Professor Adjunto da Universidade Federal da Bahia.

Marco Aurélio Holanda de Castro

Engenheiro Civil, PhD pela Drexel University -USA. Professor Adjunto do Departamento de Engenharia Hidráulica e Ambiental da Universidade Federal do Ceará,

(*) Endereço para correspondência: Rua Nadir Saboya, 980 - Casa 28 - Bairro: Sapiranga. CEP: 60833-344. Fortaleza - CE

Tel: (85) 9973.4672 - email: gweyne@hotmail.com 


\section{Introdução}

Os sistemas de abastecimento de água, esgotamento sanitário e a coleta de resíduos sólidos constituem os mais importantes fatores que contribuem para o nível sanitário de um país. Apesar de reconhecida a importância destas infraestruturas de saneamento básico, a situação no Brasil requer atenção, esforços e subsídios para uma resolução, mesmo que parcial.

O Brasil é um país com pequena abrangência no que se refere aos sistemas de esgotamento sanitário. Segundo BRASIL (2004), o atendimento urbano é muito precário e o índice médio nacional é de $50,4 \%$. Somente dois prestadores de serviços de abrangência regional atendem a mais de 50\% da população urbana dos municípios a que serve em um subconjunto em que a média é de 38,6\%. Já para os prestadores locais os índices são melhores, sendo que cerca de $48 \%$ desses prestadores apresentam valores iguais ou superiores a 50\%, em um cenário em que a média do subconjunto é de $76,2 \%$.

Estes dados delineiam o quanto o Brasil está aquém do nível satisfatório no que concerne aos sistemas de esgotamento sanitário. Tais índices promovem ainda mais a busca por novas tecnologias relacionadas à construção, implantação e manutenção dos sistemas de esgotos.

Diante da necessidade de construção ou ampliação dos sistemas de esgotos sanitários, os processos de planejamento, projeto e obra devem estar organizados de forma a serem realizados dentro do cronograma estipulado, levando em conta a racionalização de recursos e prazos.

Dado que uma rede de esgoto utiliza a energia resultante das diferenças de cotas entre os extremos de montante e jusante, a escolha dos diâmetros das tubulações e das respectivas declividades constitui o problema fundamental no processo de dimensionamento.

Por outro lado, as características dos esgotos obrigam que o escoamento seja dado mediante certas condições, de forma que se mantenha o adequado funcionamento hidráulico-sanitário da rede.

Dentro destas condições ressaltam-se as de autolimpeza (dada pela tensão trativa), as quais correspondem assegurar um valor mínimo da velocidade de escoamento ou do poder de transporte e, consequentemente, uma declividade mínima dos coletores.

Em resumo, o dimensionamento da rede está condicionado, por um lado, pelas perdas de energia que devem ser mantidas, sempre que possível, dentro dos limites disponíveis e, por outro, pela utilização desta energia de forma a que sejam mantidas as condições de autolimpeza.

Dentre os quantitativos que podem levar à redução do custo das redes coletoras, podem-se citar: volume de escavação, área de escoramento, extensões das tubulações etc. Entretanto, a determinação de um dimensionamento ótimo consiste na determinação da melhor combinação de diâmetro e declividade.

\section{Objetivos e justificativa}

Este trabalho tem como objetivo geral propor o modelo computacional que realiza uma análise de custos em redes coletoras de esgoto sanitário, com a finalidade de apresentar o menor custo de instalação e garantir o comportamento hidráulico-sanitário dentro das normas vigentes.

Utilizou-se o BASIC como linguagem de programação, por meio do compilador VISUAL BASIC 6. Este compilador foi escolhido com o intuito de promover a integração entre o AutoCAD e a rotina de dimensionamento hidráulico - o UFC9 - detalhada em Rodrigues (2006).

Dentre as técnicas de programação disponíveis atualmente, a Busca Exaustiva (BE) foi a ferramenta escolhida por oferecer uma completa exploração do espaço de busca, aliado à possibilidade do uso de variáveis discretas. Além disso, a técnica é de manipulação razoável, o que facilita a sua conectividade com modelos de simulação.

Os objetivos específicos desta pesquisa são:

- Aplicar um algoritmo híbrido de busca exaustiva em largura, a fim de minimizar os custos em projetos de redes coletoras de esgotos sanitários, aproveitando a interface do UFC9.

- Comparar as soluções de projetos de redes reais com as soluções ótimas globais geradas a partir do modelo desenvolvido.

- Aplicar e avaliar o modelo, considerando o método da pesquisa, em dois estudos de caso reais.

\section{Algoritmos de busca exaustiva}

Os algoritmos de busca são aqueles que realizam um caminhamento para explorar um grafo examinando todos os seus vértices e arestas. Existem muitos destes algoritmos, sendo que cada um possui uma estratégia específica que é caracterizada pela ordem em que os vértices são visitados. Há diversos problemas cujas soluções têm o potencial de serem encontradas por meio de métodos de busca. Estes 
métodos dividem-se em informados ou não informados (busca cega).

Os primeiros utilizam alguma informação específica do problema para gerar um novo estado. Geralmente, é utilizada uma função de avaliação heurística que procura estimar quantos passos são necessários para chegar à solução. Os de busca cega não utilizam qualquer conhecimento específico do problema para determinar a prioridade com que os nós serão expandidos.

Estes algoritmos também são utilizados para encontrar uma sequência de ações que, partindo de um estado inicial, levem a uma determinada configuração desejada. São avaliados, comumente, de acordo com a completude, ou seja, se conseguem chegar a uma solução ótima (otimalidade).

Uma das técnicas de resolução de problemas é gerar todas as possíveis soluções e verificar qual delas é de fato a procurada ou ótima. Esta técnica é denominada busca exaustiva, pois percorre todo o espaço de possíveis soluções em busca da mais pertinente para cada caso.

A busca em largura (ou busca em amplitude) está intimamente relacionada com o conceito de distância entre vértices. Quando aplicada a uma arborescência, a busca em amplitude faz uma varredura por níveis. Por outro lado, a busca em profundidade é um algoritmo utilizado para realizar uma busca ou travessia em uma árvore, estrutura de árvore ou grafo. $\mathrm{O}$ algoritmo começa em um nó raiz e explora tanto quanto possível cada um dos seus ramos, antes de retroceder.

Tipicamente uma solução por busca exaustiva (ou força bruta) é composta de duas funções: uma que gera todas as possíveis soluções e outra que verifica se a solução gerada é a que atende ao problema. O principal entrave deste modo de busca é de que pode existir um número muito grande de soluções a serem verificadas.

O algoritmo supracitado possui uma implementação relativamente simples e sempre encontrará uma solução se ela existir. Contudo, o custo computacional é proporcional ao número de candidatos à solução que, em problemas reais, tende a crescer exponencialmente e não linearmente. Consequentemente, a força bruta é tipicamente empregada em problemas cujo tamanho é limitado, ou quando há uma heurística usada para reduzir o conjunto de candidatos para um espaço considerado aceitável. $\mathrm{O}$ uso deste tipo de busca pode ser também empregado quando a simplicidade da implementação é mais importante que a velocidade de execução.

\section{Considerações metodológicas}

O cálculo manual de quantitativos em redes de abastecimento de água e esgotamento sanitário é lento e, muitas vezes, de precisão duvidosa, devido às quantidades que são estimadas ou arbitradas em vários itens pertencentes ao orçamento. No âmbito desse trabalho, o objetivo consiste na minimização do custo com a rede coletora de esgotos sanitários.

A construção da rede coletora é um dos fatores de maior peso no custo global de obras de sistema de esgotamento sanitário. Sendo que, para reduzir os custos de implantação desta etapa, os projetistas passaram a utilizar tecnologias mais econômicas e de fácil execução, como os tubos de PVC (Policloreto de Vinila) e/ou PEAD (Polietileno de Alta Densidade) em substituição aos materiais que eram comumente utilizados (concreto, manilha cerâmica etc.).

O processo do modelo computacional foi iniciado a partir do aplicativo UFC9 para traçado e dimensionamento hidráulico de redes coletoras de esgoto, desenvolvido pelo Laboratório de Hidráulica Computacional da Universidade Federal do Ceará. O UFC9 é baseado na geometria e hidráulica dos coletores de esgoto e foi tema de estudo de Rodrigues (2006).

A base de cálculo de quantitativos é o UFC9-Q, módulo criado para a geração de quantitativos e custos. O modelo desta pesquisa foi integrado ao UFC9 por intermédio de uma rotina computacional suplementar para a aplicação específica do método de redução de custos.

O referido aplicativo vem sendo difundido e utilizado em instituições públicas e privadas nos últimos anos, o que suscitou confiabilidade e demonstra a aplicabilidade em projetos na área de saneamento. O programa deste trabalho foi denominado Ferramenta Auxiliar de Redução de Custos (FARC) para o UFC9.

Os passos de maior dificuldade na elaboração dos quantitativos para redes de esgoto consistem em se estimar os volumes de escavação e áreas de escoramento de toda a rede. Nenhum programa ou planilha que se tenha conhecimento, até então, possuía capacidade de precisar este cálculo sem utilizar para as profundidades das singularidades de montante e jusante médias e/ou regressões lineares para se avaliar tais quantidades, conforme pode ser constatado em Magalhães (1995). Este trabalho é enfadonho e requer experiência do profissional, sendo necessários além de um estudo de sondagem, todos os perfis longitudinais dos coletores para um cálculo mais preciso. 
Cynamon (1986) enumera alguns fatores que contribuem para o aumento dos custos nos sistemas de esgotos. Em geral, pode-se citar: em coletores de até $400 \mathrm{~mm}$ (substituindo-se poços de visita por tubos de inspeção e limpeza); diâmetro da tubulação; profundidade das valas; implantação de estações elevatórias; exigência das normas.

Para este último item, pode ser dado como exemplo o fato de uma norma da Associação Brasileira de Normas Técnicas (NBR 14486/2000) ter sido lançada para tubos de PVC, na qual fixa a tensão trativa mínima em 0,6 $\mathrm{Pa}$, que pode ser constatada em ABNT (2000).

A profundidade de escavação está diretamente associada à declividade do coletor. Existe, sob o ponto de vista econômico, uma compensação entre o diâmetro e a profundidade. Geralmente, a um diâmetro menor corresponde uma maior declividade e, consequentemente, uma maior profundidade de escavação, sendo a recíproca verdadeira.

A afirmação anterior implica que a definição dos diâmetros e das declividades dos tubos, de modo que se garanta um adequado funcionamento hidráulico-sanitário da rede, constitui uma tarefa mais complexa e difícil do que em princípio pode aparentar

Dado que uma rede é constituída por um grande número de tubos e órgãos acessórios, existem várias combinações possíveis para seus diâmetros e declividades, o que exige ao projetista particular intuição e experiência.

No dimensionamento convencional, ou seja, de forma manual (o que pode ser considerado ultrapassado com o advento da tecnologia dos computadores), a análise econômica limita-se a um número restrito de combinações tecnicamente viáveis, sendo essas combinações consideradas como o conjunto de diâmetros e declividades que garantem uma tensão trativa mínima exigida por ABNT (1986).

O principal entrave deste procedimento manual consiste no fato de as decisões sobre as combinações de diâmetros e declividades serem feitas sem uma análise simultânea e sistemática das implicações econômicas, o que pode conduzir a não consideração de algumas combinações que seriam economicamente mais relevantes.

Para a combinação ótima do binômio declividade/diâmetro, um cenário sem a ajuda de microcomputadores para a resolução deste problema é bastante desfavorável. A aplicação de modelos computacionais para a unificação dos processos de dimensionamento, quantificação e redução de custos é o que se propõe para este trabalho, como forma de atenuar o dispêndio de tempo entre estas etapas.

A figura 1 ilustra o fluxograma proposto com todas as etapas que irão compor o UFC9, tanto as já desenvolvidas em Rodrigues (2006), como a idealizada nesta pesquisa.

Metodologia utilizada - ferramenta auxiliar de redução de custos

Nos últimos anos, dentre os vários algoritmos utilizados na otimização em redes coletoras de esgoto sanitário, nunca foi utilizado um algoritmo de busca exaustiva com o objetivo de percorrer toda a rede e que arbitrasse os diâmetros para cada trecho, verificando e atendendo a todas as restrições hidráulicas. Este é a meta primordial desta pesquisa.

Uma característica comum, em se tratando de otimização em redes de esgotos, é que a principal variável de decisão é o diâmetro dos coletores. Considerar o diâmetro uma variável de decisão contínua levanta o problema de arredondamento do diâmetro teórico calculado para o diâmetro comercial mais próximo. Por outro lado, considerar o diâmetro uma variável de decisão discreta conduz a um excessivo tempo e capacidade de memória de um computador para a obtenção da solução.

As dificuldades decorrentes dos diâmetros dos coletores serem considerados variáveis de decisão contínuas ou discretas constituíram, desde o início da formulação do modelo, uma das preocupações principais.

Para a formulação do modelo computacional uma série de restrições deve ser seguida em relação ao dimensionamento hidráulico de redes coletoras de esgoto sanitário, como: diâmetro mínimo regulamentar; aumento progressivo dos diâmetros da rede, conforme a NBR 9649/1986; limite superior para a velocidade de escoamento; tensão trativa mínima; profundidade de assentamento mínima dos coletores medida sob sua geratriz.

As duas primeiras restrições são implicitamente consideradas no modelo, dado que este último inicia somente após a atribuição do diâmetro mínimo da rede em todos os trechos. Nestas condições, compete ao tomador de decisão selecionar os diâmetros de tal forma que sejam maiores ou iguais ao mínimo regulamentar. A terceira e quarta restrições são de caráter exclusivamente hidráulico.

O formato da função objetivo e a sua definição pressupõem um conhecimento prévio do tipo das funções de custo, a partir das quais se relacionam o custo de uma componente do sistema com os dados 


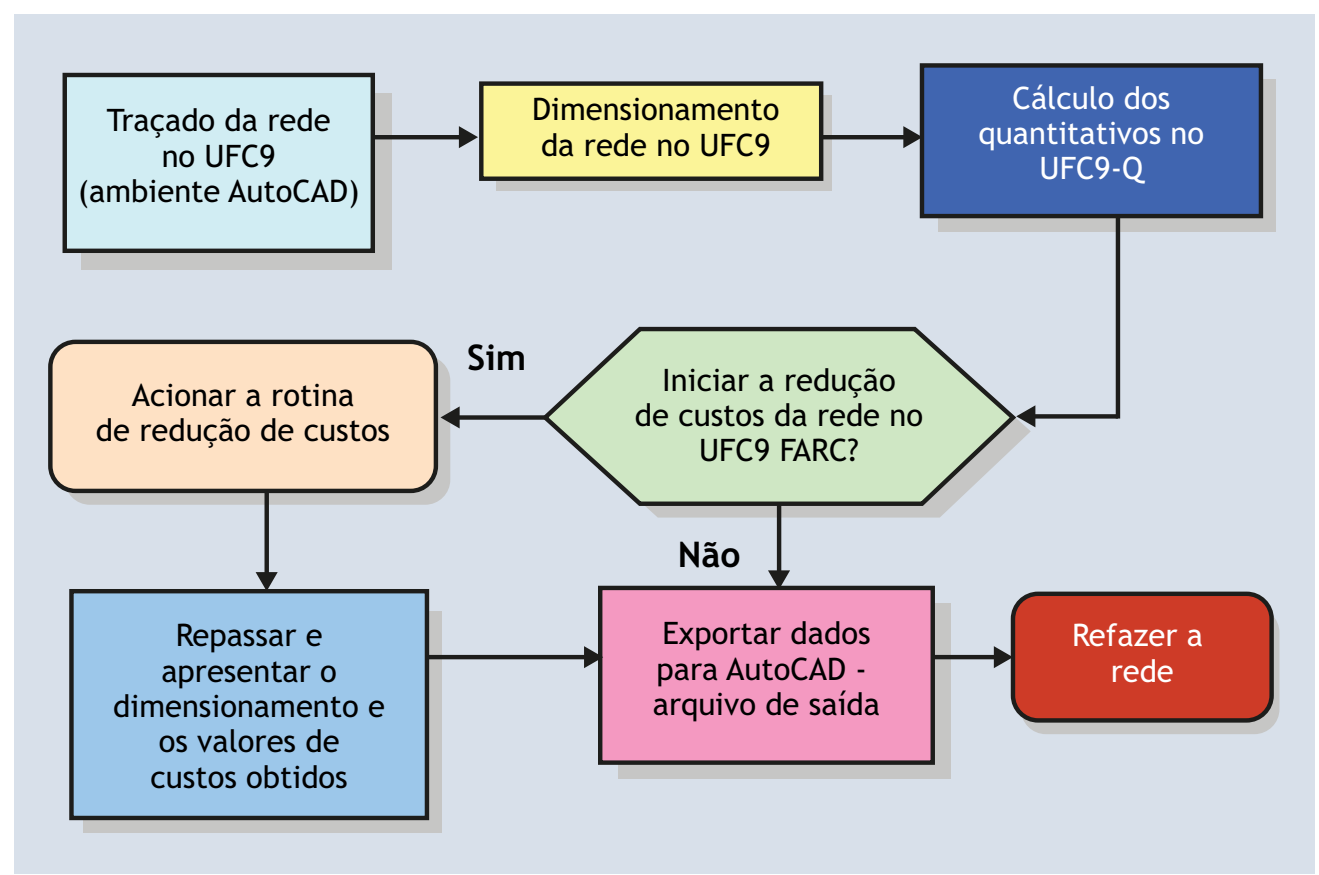

Figura 1: Fluxograma do método proposto (Sistema UFC9)

de entrada. Definem-se estas funções referentes às de transporte e superior para a velocidade; fixam-se, também, os limites inferior e superior para a declividade de cada coletor.

As restrições correspondentes à profundidade de assentamento mínima dos coletores, medida sobre a sua geratriz, exigem que a diferença entre as cotas do terreno e da geratriz do coletor seja, em qualquer ponto da rede, maior ou igual a um valor mínimo especificado.

As cotas das geratrizes dos coletores em cada um dos seus extremos de montante e jusante podem ser obtidas a partir das declividades, dos comprimentos, dos poços de visita e da cota da soleira na extremidade de jusante do primeiro coletor no trecho.

Em princípio, seria de esperar que para cada coletor tivessem de ser escritas duas restrições: uma para o seu extremo de jusante e outra para o seu extremo de montante. No entanto, dado que terá de se manter o aumento progressivo das cotas das geratrizes superiores interiores dos coletores da rede, de jusante para montante, só será necessária a restrição correspondente ao extremo de jusante. Salvo os casos correspondentes aos coletores de cabeceira da rede, para os quais a restrição tem de ser escrita, também, para o extremo de montante.

Em relação à redução de custos, neste trabalho a função objetivo expressa a soma dos custos de investimento de serviços da rede coletora (movimento de terra, escoramento, execução de poços de visita, tubos de queda, locação, cadastro, trânsito e segurança etc.) e fornecimento de material.

A expressão de custos da equação 1 representa a função objetivo a ser minimizada.

$$
C t=\sum_{i=0}^{N T}(C \operatorname{serv}+C m a t)
$$

$$
\begin{aligned}
& \text { Onde: } \\
& C t \quad \rightarrow \text { custo total da rede }[R \$] \\
& N T \quad \rightarrow \text { número de trechos da rede [unidade] } \\
& \text { Cserv } \rightarrow \text { custos dos serviços da rede }[R \$] \\
& \text { Cmat } \rightarrow \text { custos do fornecimento de material da rede }[R \$]
\end{aligned}
$$

A FARC é o módulo que contém todos os passos para a análise e redução de custos de uma rede coletora de esgotos. A partir do arquivo de um arquivo de entrada, gerado pelo UFC9, o modelo inicia as instruções para a busca exaustiva da rede. Este arquivo fornece o comprimento do trecho, singularidades de montante e jusante, vazões concentradas, profundidades de montante e jusante etc., para que, 
posteriormente, o algoritmo possa realizar o dimensionamento de todas as soluções com os dados fornecidos. A solução inicial do UFC9 serve de base para o reconhecimento do modelo de quais são os diâmetros mínimos a serem utilizados em cada trecho da rede.

A hibridez do algoritmo se dá pela geração de 1 a n nós iniciais ou "pais". Onde n corresponde ao número de trechos que são pontas-secas, ou seja, não recebem contribuição a montante. Tais trechos são os primeiros a serem calculados em redes de esgotos, como indica o algoritmo das vazões em Rodrigues (2006). No algoritmo de busca em largura comum, inicia-se com apenas um nó "pai". Nesta hibridez, destaca-se também a existência de um último nó único.

A partir de todos os trechos pontas-secas, são arbitrados diâmetros (predeterminados) para todos os trechos subsequentes da rede, formando assim uma árvore, que cresce em largura e profundidade. Nesta pesquisa, como citado anteriormente, o mate- rial utilizado na tubulação é o PVC. A gama de diâmetros comerciais do PVC varia em 100, 150, 200, 250, 300, 350 e $400 \mathrm{~mm}$.

Para redes maiores que nove trechos, no modelo deste trabalho, foram requeridos longos tempo de processamento, apesar da velocidade de processamento dos computadores da atualidade. Baseado nestas constatações utilizou-se das considerações de Argaman et al (1973), subdividindo as redes de maior porte em menores. Seguindo sugestões de Mays e Yen (1975), em redes de muitos coletores, a metodologia decompõe a rede em sub-redes, cada uma como se não houvesse trechos secundários ("non-serial approach").

O fluxograma do algoritmo proposto é ilustrado na figura 2 .

Com este algoritmo, percorre-se todo o espaço de busca da rede, ou seja, todas as soluções. Dentre as soluções factíveis, dimensiona-se e calcula-se o custo de cada uma, apresentando em seguida a de menor custo.

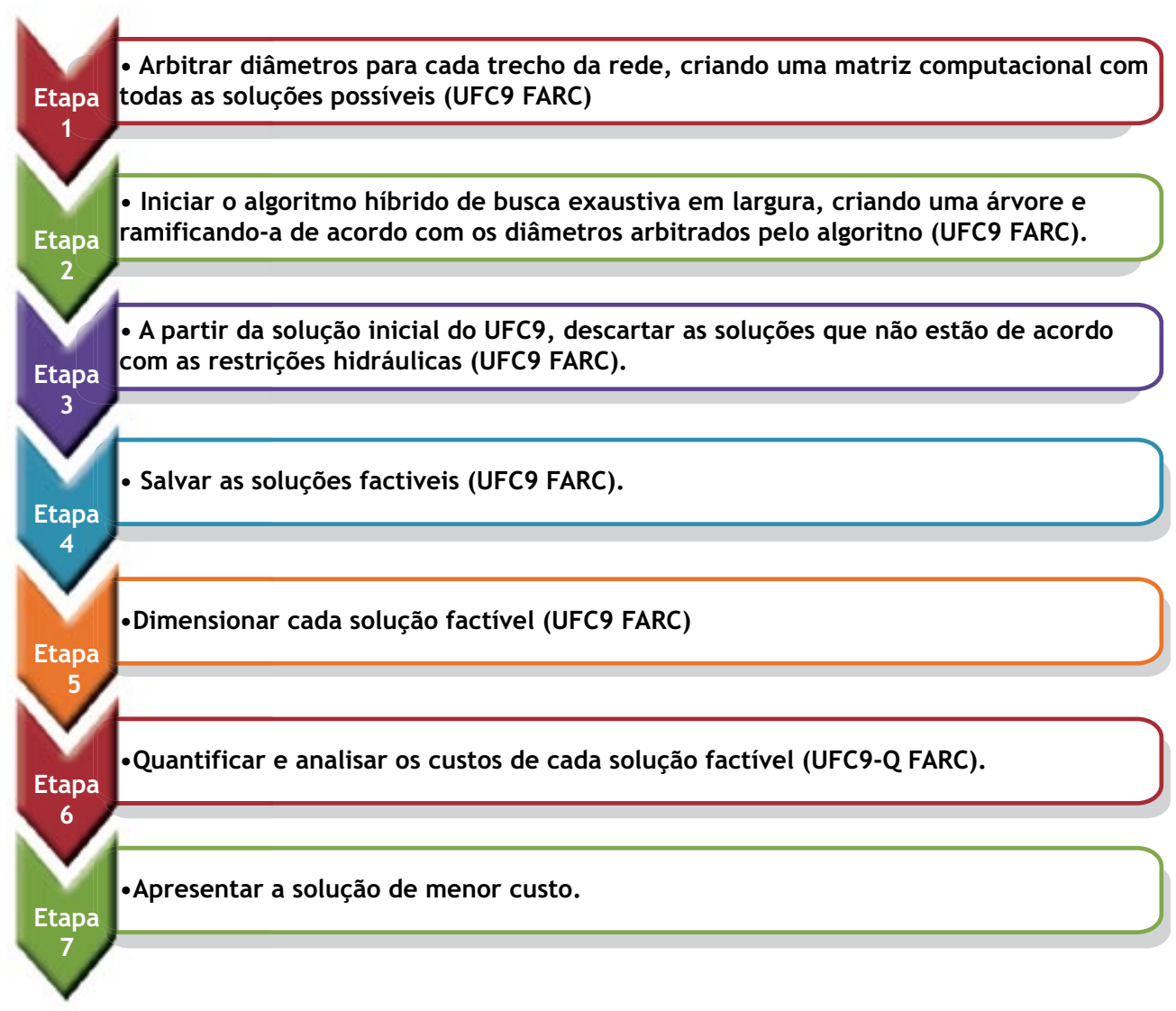

Figura 2: Fluxograma do algoritmo proposto 


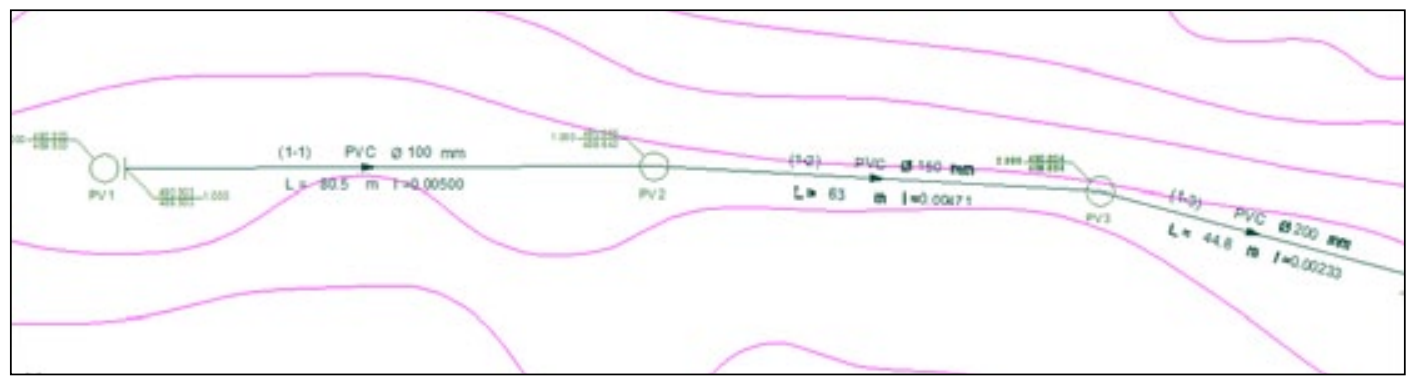

Figura 3: Rede exemplo do algoritmo proposto

\section{Exemplificação do modelo proposto}

Seja uma rede coletora de esgotos com 3 trechos em PVC (figura 3) e uma gama de apenas 3 (três) diâmetros disponíveis (100, 150 e 200 mm). Nomeando-se os trechos em 1-1, 1-2 e 1-3, com os referidos diâmetros em forma de vetor, produzem-se uma solução $\left(\mathrm{S}_{0}\right)$ e custo iniciais $\left(\mathrm{C}_{0}\right)$ : $\mathrm{S}_{0}$ : [100; 150; 200] $\rightarrow \mathrm{C}_{0}$

O algoritmo de busca impõe os diâmetros predeterminados (solução inicial do UFC9) partindo dos trechos pontas-secas, seguindo o caminho até o fim da rede. No exemplo, o caminho é realizado da seguinte maneira:

- Trecho 1-1 (ponta-seca e, assim, nó inicial) [100 mm];

- Trecho 1-2 [150 mm];

- Trecho 1-3 (nó final/último trecho) [200 mm] A figura 4 exibe todas as soluções possíveis (para 3 diâmetros e 3 trechos). Entre estas soluções encontram-se as factíveis e não factíveis. Uma matriz (variável computacional) foi criada para armazenar todas as soluções. O número de soluções possíveis é determinado pela quantidade de diâmetros disponíveis elevado ao número de trechos, como se constata na equação 2. Para o exemplo, tem-se $33=27$, logo são 27 (vinte e sete) soluções - factíveis e infactíveis.

Segue-se a sequência até o final da rede. A altura

$$
\mathrm{NST}=\mathrm{NDD}^{\mathrm{NT}}
$$

\footnotetext{
Onde:

NST $\rightarrow$ número de soluções totais

$N D D \rightarrow$ número de diâmetros disponíveis

NT $\rightarrow$ número de trechos da rede.
}

máxima da árvore é o maior caminho entre os pontos inicial e final. As próximas etapas consistem em marcar os galhos das soluções não factíveis, reduzindo significativamente o número de soluções, enviando para a etapa seguinte apenas as factíveis (filtro 1). As soluções inviáveis são aquelas que não são condizentes com as restrições hidráulicas.

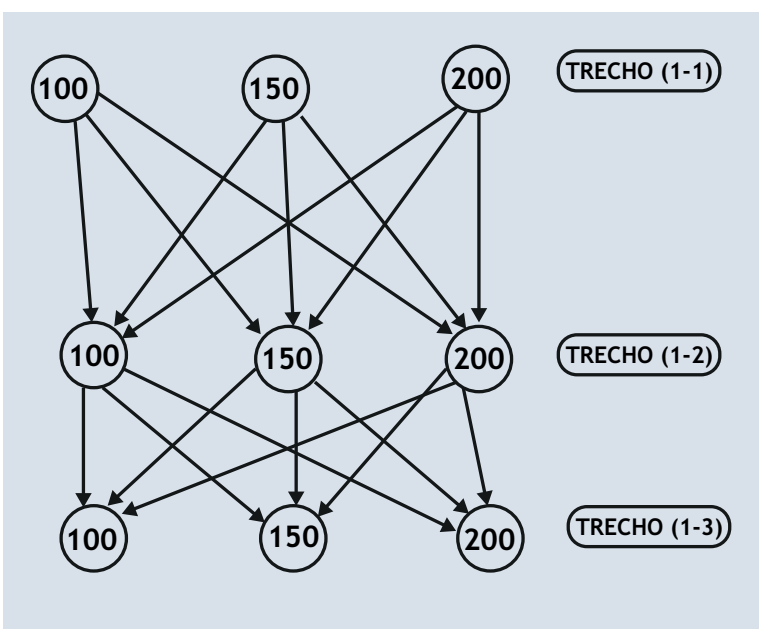

Figura 4: Esquema de ramificação da árvore do exemplo (todas as soluções)

Quando o algoritmo de busca parte de uma solução inicial, mais reduzidas ficam as soluções viáveis, pela exigência da norma em relação à progressividade dos diâmetros (denominou-se filtro 2). Isto se deve ao fato, no exemplo, de o trecho 1-2 não poder ser menor que $150 \mathrm{~mm}$. Como a solução inicial é hidraulicamente viável, para este caso, eliminar-seiam para o trecho 1-3 os diâmetros inferiores a 200 $\mathrm{mm}$, bem como para o trecho 1-2 o diâmetro não poderia ser inferior a $150 \mathrm{~mm}$.

As implicações das considerações acima estão 
esboçadas nas figuras 5 e 6 , onde se verifica a vertiginosa redução de soluções infactíveis - somente as viáveis estão apresentadas. Com o primeiro filtro aplicado, as soluções passam a ser 10 (dez) e, com o segundo filtro, caem para 5 (cinco), sendo, respectivamente, $37,04 \%$ e $18,54 \%$ de todas as possíveis.

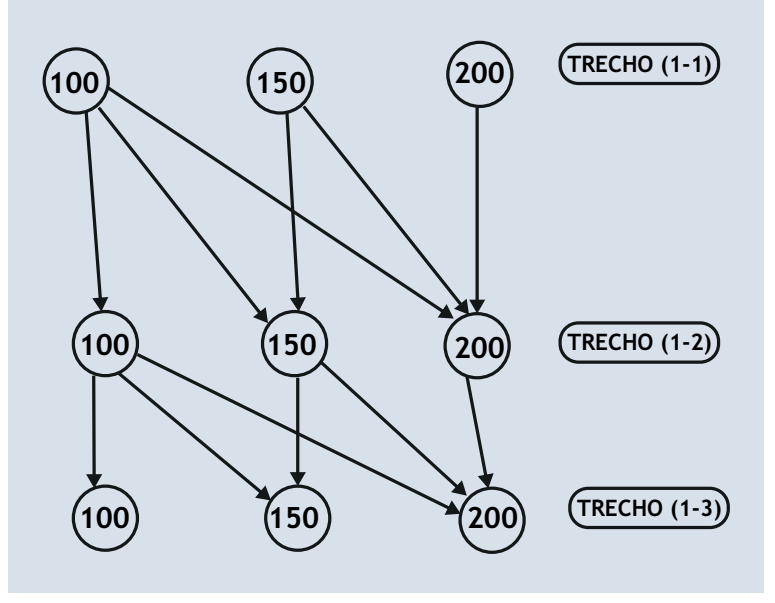

Figura 5: Soluções factíveis da árvore do exemplo (filtro 1)

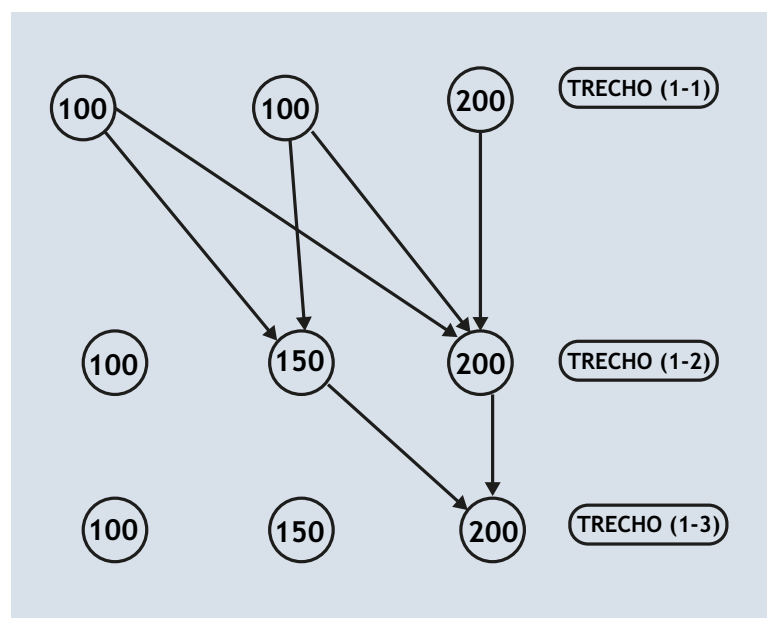

Figura 6: Soluções factíveis da árvore do exemplo (filtro 2)

\section{Resultados e discussões}

Nas aplicações do modelo proposto foram utilizados dois estudos de caso em redes reais. Estes foram baseados foram baseados em dois projetos executivos de sistemas de esgotamento sanitário. Cada estudo de caso possui uma particularidade específica.

Foram efetuadas comparações dos resultados dos modelos da pesquisa com os valores originais dos projetos executivos referentes aos sistemas de co- leta de esgoto sanitário das cidades de Rio Tinto/PB (Bacia X) e Brejo dos Santos/PB (Bacia 5). Em todas as redes excluiu-se o diâmetro de $100 \mathrm{~mm}$, ou seja, o mínimo utilizado foi de $150 \mathrm{~mm}$ (seguindo a NBR 9649/1986).

Como já se dispunha dos resultados finais dos projetos destas localidades, foram traçadas no UFC9 redes idênticas às originais, conservando, assim, diâmetros, comprimento, singularidades, diâmetro mínimo, cotas de terreno e numerações.

Com o objetivo de expressar os resultados com a maior fidedignidade possível, os projetos foram repassados ao UFC9 com os mesmos parâmetros de projeto como: material da tubulação, diâmetros, recobrimento mínimo, taxas de contribuição linear, degrau mínimo, altura mínima do tubo de queda, extensão virtual da rede, conforme as tabelas 1 e 5, respectivamente, para Rio Tinto e Brejo dos Santos.

Ademais, não se poderiam fazer comparativos de quantidades e custos em qualquer projeto cuja memória de cálculo não estivesse detalhada passo a passo, sem os cálculos particularizados, principalmente dos volumes de escavação que, em sua maioria, são estimados.

Por este motivo, optou-se repassar os projetos para o UFC9 (com os mesmos dados de topografia) e, a partir deste aplicativo, realizaram-se os estudos comparativos balizados em uma mesma metodologia (FARC) para se avaliar o desempenho do algoritmo em relação aos principais custos envolvidos (diâmetros e assentamento das tubulações, volume de escavação, escoramento).

A rede da bacia X (figura 7) do sistema de esgotamento sanitário da cidade de Rio Tinto (Estado da Paraíba) é composta de 23 trechos, 23 poços de visita e 1.721,50 m de extensão. A coleta é encaminhada para uma estação elevatória de esgoto bruto (EEEB3), de onde este é recalcado para outra bacia. A rede é, quase em sua totalidade, a favor da declividade natural do terreno, porém possui trechos que recebem vazões pontuais oriundas de outras bacias, o que ocasiona aumento dos volumes de esgotos. Estas contribuições estão detalhadas na tabela $1 \mathrm{e}$ os parâmetros principais da rede estão apresentados na tabela 2.

Com uma rede de 23 trechos, seria requerido um longo tempo de processamento computacional para a utilização da FARC, conforme explanado anteriormente. Logo, a rede foi dividida em 5 sub-bacias como meio para acelerar os cálculos computacionais.

Como esperado, para as sub-bacias de 2 a 5 os 


\section{Artigo Técnico}

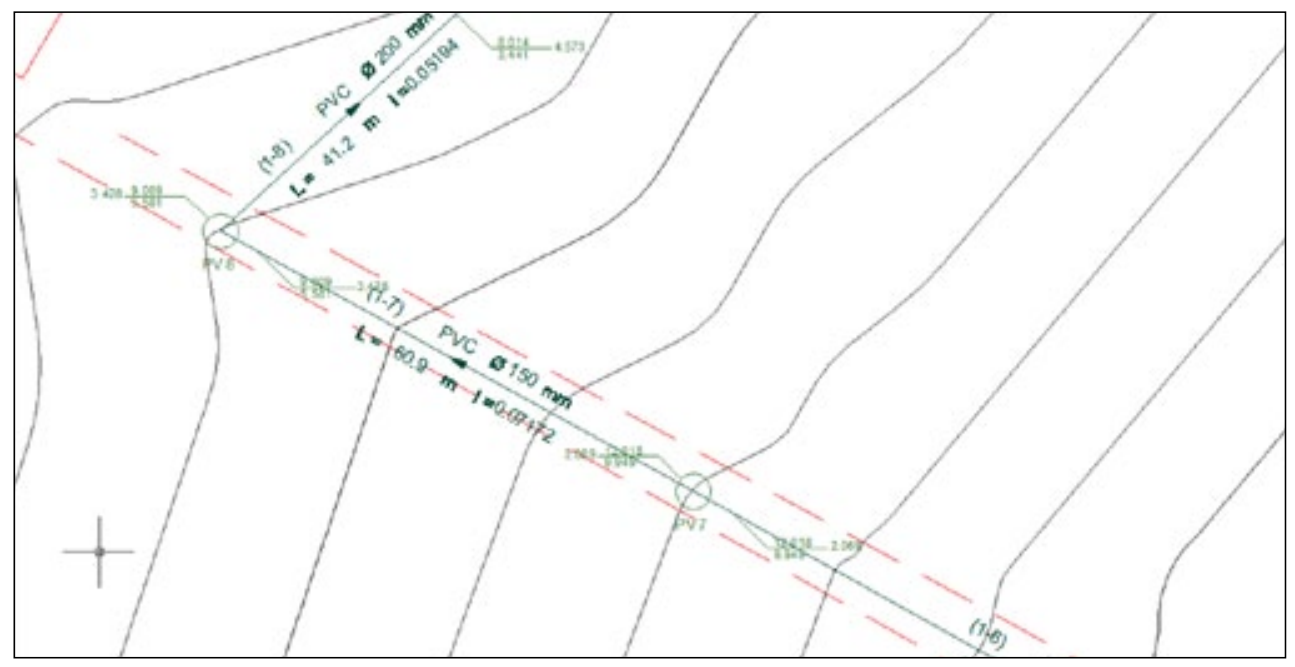

Figura 7: Setor da rede real do estudo de caso 1

\begin{tabular}{|c|c|c|c|} 
Trecho & PV de montante & $\begin{array}{c}\text { Vazão concentrada de } \\
\text { início de plano (L/s) }\end{array}$ & $\begin{array}{c}\text { Vazão concentrada } \\
\text { de fim de plano (L/s) }\end{array}$ \\
\hline$(1-4)$ & PV4 & 5,12 & 9,56 \\
\hline$(1-5)$ & PV5 & 15,77 & 28,43 \\
\hline$(1-6)$ & PV6 & 20,93 & 38,78 \\
\hline
\end{tabular}

Tabela 1: Vazões concentradas da rede real do estudo de caso 1

\begin{tabular}{l|c} 
Característica & Valor \\
\hline Número de trechos & 23 \\
\hline Número de poços de visita & 23 \\
\hline Material da tubulação & PVC \\
\hline Diâmetro mínimo & $150 \mathrm{~mm}$ \\
\hline Recobrimento mínimo & $0,90 \mathrm{~m}$ \\
\hline Degrau mínimo & $0,05 \mathrm{~m}$ \\
\hline Altura mínima do tubo de queda & $0,50 \mathrm{~m}$ \\
\hline Taxa de contribuição linear (início de plano) & $0,00433(\mathrm{~L} / \mathrm{s}, \mathrm{m})$ \\
\hline Taxa de contribuição linear (fim de plano) & $0,00868(\mathrm{~L} / \mathrm{s}, \mathrm{m})$ \\
\hline Extensão virtual da rede & $1362,60 \mathrm{~m}$ \\
\hline Lâmina líquida máxima & 0,75 \\
\hline Tensão trativa mínima & $1,0 \mathrm{~Pa}$ \\
\hline Coeficiente de retorno & $80 \%$ \\
\hline Coeficiente per capita & $120(\mathrm{~L} / \mathrm{hab}, \mathrm{dia})$ \\
\hline Coeficiente de infiltração & $0,0001(\mathrm{~L} / \mathrm{s} / \mathrm{m}$ \\
\hline Coeficiente K1 & 1,2 \\
\hline Coeficiente K2 & 1,5 \\
\hline
\end{tabular}

Tabela 2: Parâmetros da rede real do estudo de caso 1 
resultados obtidos pela FARC não foram melhores que os cálculos iniciais do UFC9 utilizando-se dos parâmetros do projeto, haja vista que os coletores estão seguindo o terreno natural e não há vazões pontuais. Na subbacia 1, incluíram-se além das vazões pontuais oriundas de outras bacias as vazões lançadas pela sub-bacias 2 a 5 , conforme a tabela 3.

\begin{tabular}{c|c|c|c|c|c}
$\begin{array}{c}\text { Trecho } \\
\text { contribuinte }\end{array}$ & $\begin{array}{c}\text { Trecho da } \\
\text { sub-bacia 1 } \\
\text { que recebe a } \\
\text { contribuição }\end{array}$ & $\begin{array}{c}\text { Sub-bacia de } \\
\text { origem }\end{array}$ & $\begin{array}{c}\text { PV da sub-bacia } \\
\text { 1 que recebe as } \\
\text { vazões }\end{array}$ & $\begin{array}{c}\text { Vazão lançada de } \\
\text { início de plano } \\
\text { (L/s) }\end{array}$ & $\begin{array}{c}\text { Vazão lançada de } \\
\text { fim de plano (L/s) }\end{array}$ \\
\hline$(2-3)$ & $(1-4)$ & 2 & PV4 & 1,0197 & 2,0441 \\
\hline$(3-3)$ & $(1-3)$ & 3 & PV3 & 1,0245 & 2,0537 \\
\hline$(4-3)$ & $(1-2)$ & 4 & PV2 & 1,0448 & 2,0945 \\
\hline$(5-6)$ & $(1-8)$ & 5 & PV8 & 0,7335 & 1,4704 \\
\hline
\end{tabular}

Tabela 3: Vazões lançadas pelas sub-bacias 2 a 5 na sub-bacia 1 (estudo de caso 1)

A sub-bacia 1 foi dimensionada no UFC9 com todas as características assinaladas acima e de acordo com os diâmetros apontados em projeto (sem a rotina de redução de custos) e, posteriormente, foram gerados os quantitativos e custos.

O número total de soluções para este caso é de 68, ou seja, 1.679.616. Utilizando-se o modelo, as soluções factíveis caem para 1.287 com a aplicação do filtro 1 e 1.286 com o filtro 2 aplicado, como pode ser constatado na tabela 4.

\begin{tabular}{c|c|c} 
Soluções & Número de soluções & $\begin{array}{c}\text { Percentual em relação ao } \\
\text { número total de soluções }\end{array}$ \\
\hline Total (sem filtros) & 1.679 .616 & - \\
\hline Factíveis (filtro 1) & 1.287 & $0,077 \%$ \\
\hline Factíveis (filtro 2) & 1.286 & $0,077 \%$ \\
\hline
\end{tabular}

Tabela 4: Número de soluções e percentuais para a rede real do estudo de caso 2 (sub-bacia 1)

O custo da solução inicial da sub-bacia 1 está exibido na tabela 5, tendo o valor total de R $\$ 70.751,09$. Com a conclusão do modelo computacional, o menor custo determinado foi de $\mathrm{R} \$ 61.316,44$, ou seja, houve uma redução de 15,39\% em relação ao custo inicial. Para toda a rede, o percentual de redução cai para 4,88\% e os custos de $\mathrm{R} \$ 202.628,05$ reduziram para $\mathrm{R} \$ 1$ 193.193,40 (tabela 6). A FARC proporcionou uma considerável redução nos custos no que se refere ao binômio aumentar o diâmetro de coletores com o intuito de reduzir o volume de escavação e área de escoramento.

\begin{tabular}{|c|c|c} 
Solução & Valor (R\$) & $\begin{array}{c}\text { Percentual de redução em relação } \\
\text { à solução inicial }\end{array}$ \\
\hline Inicial - sem aplicação do modelo & $70.751,09$ & - \\
\hline Ótima - com aplicação do modelo & $61.316,44$ & 15,39
\end{tabular}

Tabela 5: Valores e percentual de redução dos custos para a sub-bacia 1 do estudo de caso 1 


\begin{tabular}{c|c|c}
\multicolumn{1}{c|}{ Solução } & Valor (R\$) & $\begin{array}{c}\text { Percentual de redução em relação } \\
\text { à solução inicial }\end{array}$ \\
\hline Inicial - sem aplicação do modelo & $202.628,05$ & - \\
\hline Ótima - com aplicação do modelo & $193.193,40$ & $4,88 \%$
\end{tabular}

Tabela 6: Valores de redução dos custos para a rede real do estudo de caso 1

O algoritmo aumentou os diâmetros dos trechos (1-6) e (1-7) de $150 \mathrm{~mm}$ para $200 \mathrm{~mm}$, resultando na diminuição de profundidade. Esta configuração de diâmetros da sub-bacia 1 eliminou escavações em profundidades superiores a 4 metros e reduziu a área de escoramento, diminuindo os custos finais.

Neste caso, estudou-se a rede da bacia 3 (figura 8) do sistema de esgotamento sanitário da cidade de Brejo dos Santos, também no estado da Paraíba. Esta bacia é composta de 14 trechos, 14 poços de visita e 964,30 m de extensão. Os esgotos provenientes desta rede são lançados na bacia 1 do sistema por gravidade. Somente dois trechos da rede não seguem a declividade natural do terreno: (3-4) e (2-4).

\begin{tabular}{c|c|c|c} 
Trecho & PV de montante & $\begin{array}{c}\text { Vazão concentrada de } \\
\text { início de plano (L/s) }\end{array}$ & $\begin{array}{c}\text { Vazão concentrada de fim } \\
\text { de plano (L/s) }\end{array}$ \\
\hline$(3-4)$ & PV4 & 5,12 & 9,56 \\
\hline
\end{tabular}

Tabela 7: Vazões concentradas da rede real do estudo de caso 2

\begin{tabular}{|c|c|}
\hline Característica & Valor \\
\hline Número de trechos & 14 \\
\hline Número de poços de visita & 14 \\
\hline Material da tubulação & PVC \\
\hline Diâmetro mínimo & $150 \mathrm{~mm}$ \\
\hline Recobrimento mínimo & $0,90 \mathrm{~m}$ \\
\hline Degrau mínimo & $0,05 \mathrm{~m}$ \\
\hline Altura mínima do tubo de queda & $0,50 \mathrm{~m}$ \\
\hline Taxa de contribuição linear (início de plano) & 0,00222 (L/s.m) \\
\hline Taxa de contribuição linear (fim de plano) & 0,00434 (L/s.m) \\
\hline Extensão virtual da rede & $964,30 \mathrm{~m}$ \\
\hline Lâmina líquida máxima & 0,75 \\
\hline Tensão trativa mínima & $1,0 \mathrm{~Pa}$ \\
\hline Coeficiente de retorno & $80 \%$ \\
\hline Coeficiente per capita & 150 (L/hab . dia) \\
\hline Coeficiente de infiltração & $0,0001(\mathrm{~L} / \mathrm{s} / \mathrm{m}$ \\
\hline Coeficiente K1 & 1,2 \\
\hline Coeficiente K2 & 1,5 \\
\hline
\end{tabular}




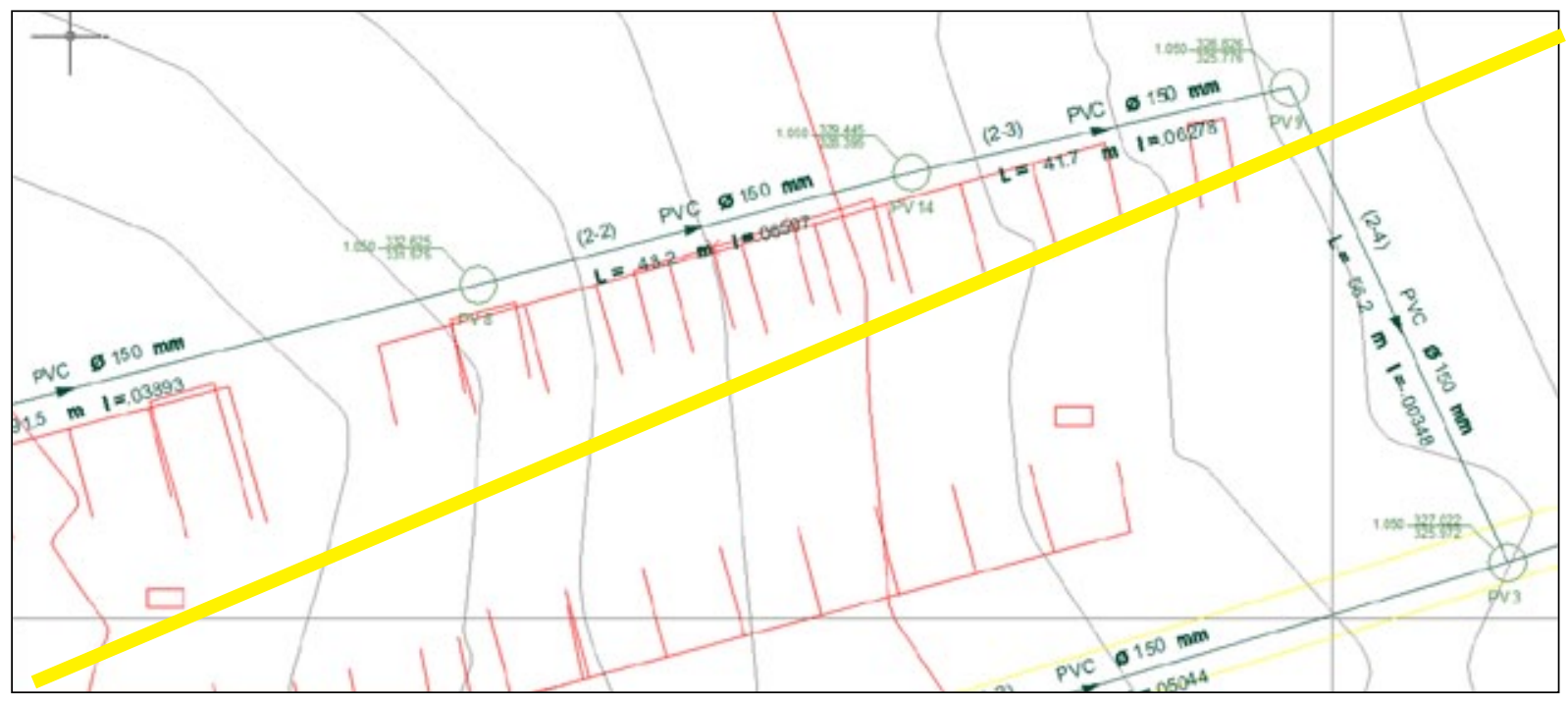

Figura 8: Setor da rede real do estudo de caso 2

Mesmo com esta peculiar característica, os coletores finais possuem vazões de alto valor, já que um trecho recebe vazão concentrada de outra bacia. A escolha desta bacia foi motivada, principalmente, por esta particularidade, pois o projeto original aprofundou bastante os trechos finais para não haver o aumento do diâmetro.

Estas contribuições de vazões estão detalhadas na tabela 7 e os parâmetros principais da rede estão apresentados na tabela 8.

Este sistema também é atualmente operado pela concessionária CAGEPA, sendo que esta é responsável pela coleta, manutenção, tratamento e disposição final.

A rede foi subdividida em 3 sub-bacias para atenuar os cálculos computacionais. Diferentemente do estudo de caso anterior, apenas para a sub-bacia 2 os resultados obtidos pela FARC foram idênticos aos cálculos iniciais do UFC9 com os diâmetros de projeto, haja vista que na sub-bacia supracitada os coletores estão seguindo o terreno natural e não há vazões pontuais (tabela 9).

\begin{tabular}{c|c|c|c|c|c}
$\begin{array}{c}\text { Trecho } \\
\text { contribuinte }\end{array}$ & $\begin{array}{c}\text { Trecho da } \\
\text { sub-bacia 1 } \\
\text { que recebe a } \\
\text { contribuição }\end{array}$ & $\begin{array}{c}\text { Sub-bacia de } \\
\text { origem }\end{array}$ & $\begin{array}{c}\text { PV da sub-bacia } \\
\text { 1 que recebe as } \\
\text { vazões }\end{array}$ & $\begin{array}{c}\text { Vazão lançada de } \\
\text { início de plano } \\
\text { (L/s) }\end{array}$ & $\begin{array}{c}\text { Vazão lançada de } \\
\text { fim de plano (L/s) }\end{array}$ \\
\hline$(2-4)$ & $(1-3)$ & 2 & PV3 & 0.5275 & 1.0312 \\
\hline$(3-4)$ & $(1-6)$ & 3 & PV6 & 21.8782 & 38.8268 \\
\hline
\end{tabular}

Tabela 9: Vazões lançadas pelas sub-bacias 2 e 3 na sub-bacia 1 (rede real do estudo de caso 2)

As sub-bacias 1 e 3 apresentaram melhores resultados com o modelo da pesquisa. Na sub-bacia 1 incluíram-se as vazões lançadas pelas sub-bacias 2 e 3, conforme a tabela 9 .

As sub-bacias 1 e 3 foram dimensionadas no UFC9 com todas as características relatadas (sem a rotina de redução de custos), mantendo-se os diâmetros do projeto original e, em seguida, foram gerados os quantitativos e custos. O número total de soluções factíveis e infactíveis é para este caso de 66 e 64 e, ou seja, 46.656 e 1.296 para as sub-bacias 1 e 3, respectivamente. Utilizando-se o modelo, as soluções factíveis caem para 126 com a aplicação do filtro 1 e 69 com o filtro 2 aplicado (em ambos os casos), como pode ser constatado por meio das tabelas 10 e 11 . 


\begin{tabular}{c|c|c} 
Soluções & Número de soluções & $\begin{array}{c}\text { Percentual em relação ao } \\
\text { número total de soluções }\end{array}$ \\
\hline Total (sem filtros) & 46.656 & - \\
\hline Factíveis (filtro 1) & 126 & $0,270 \%$ \\
\hline Factíveis (filtro 2) & 69 & $0,148 \%$
\end{tabular}

Tabela 10: Número de soluções e percentuais para a rede real do estudo de caso 2 (sub-bacia 1)

\begin{tabular}{c|c|c} 
Soluções & Número de soluções & $\begin{array}{c}\text { Percentual em relação ao } \\
\text { número total de soluções }\end{array}$ \\
\hline Total (sem filtros) & 1.296 & - \\
\hline Factíveis (filtro 1) & 126 & $9,722 \%$ \\
\hline Factíveis (filtro 2) & 69 & $5,324 \%$
\end{tabular}

Tabela 11: Número de soluções para a rede real do estudo de caso 2 (sub-bacia 3)

Na tabela 12 estão exibidos os custos das soluções inicial e final da sub-bacia 1 . O valor sem a aplicação do modelo foi de $\mathrm{R} \$ 50.390,54$ e, após a conclusão do modelo computacional, ficou em $\mathrm{R} \$ 49.303,76$. Os custos foram reduzidos em 2,204\%.

\begin{tabular}{c|c|c}
\multicolumn{1}{c|}{ Solução } & Valor (R\$) & $\begin{array}{c}\text { Percentual de redução em relação à } \\
\text { solução inicial }\end{array}$ \\
\hline Inicial - sem aplicação do modelo & $50.390,54$ & - \\
\hline Ótima - com aplicação do modelo & $49.303,76$ & $2,204 \%$
\end{tabular}

Tabela 12: Valores e percentual de redução para a sub-bacia 1 da rede do estudo de caso 2

Para a sub-bacia 3, os custos foram de $\mathrm{R} \$ 40.200,04$ para $\mathrm{R} \$ 38.254,12$, propiciando um percentual redutor de 5,087\%, conforme a tabela 13 .

\begin{tabular}{l|c|c}
\multicolumn{1}{c|}{ Solução } & Valor (R\$) & $\begin{array}{c}\text { Percentual de redução em relação } \\
\text { à solução inicial }\end{array}$ \\
\hline Inicial - sem aplicação do modelo & $40.200,04$ & - \\
\hline Melhor solução - com aplicação do modelo & $38.254,12$ & $5,087 \%$
\end{tabular}

Tabela 13: Valores e percentual de redução para a sub-bacia 3 da rede do estudo de caso 2 
No cômputo geral, o algoritmo proporcionou uma redução discreta nos custos no que se refere à escolha do diâmetro ótimo dos coletores (tabela 14).

A ferramenta computacional, na sub-bacia 3, reduziu o diâmetro do último trecho (3-4) de 300 para 250 $\mathrm{mm}$, onerando um pouco os custos com escavação e escoramento, entretanto, diminuindo os valores com o assentamento e aquisição das tubulações. A mesma estratégia foi adotada para a sub-bacia 1, também no ultimo coletor (1-6), acarretando características de compensação de valores semelhantes.

\begin{tabular}{|c|c|c|}
\multicolumn{1}{c|}{ Solução } & Valor (R\$) & $\begin{array}{c}\text { Percentual de redução em relação } \\
\text { à solução inicial }\end{array}$ \\
\hline Inicial - sem aplicação do modelo & $111.989,62$ & - \\
\hline Ótima - com aplicação do modelo & $108.956,92$ & $2,78 \%$ \\
\hline
\end{tabular}

Tabela 14: Valores e percentuais para toda rede real do estudo de caso 2

A grande demanda computacional consiste no maior problema encontrado por estes algoritmos, uma vez que estes percorrem todo o espaço de busca possível. No entanto, a análise de todas as soluções garante a ótima global.

Uma das estratégias adotadas para minimizar o tempo computacional foi a de filtrar as soluções e armazenar apenas aquelas que são hidraulicamente factíveis e, por conseguinte, calcular os quantitativos e custos destas últimas.

A outra estratégia estipulada foi a de subdividir as redes, ou seja, diminuir o número de trechos da rede para acelerar os cálculos hidráulicos e de quantitativos. Se no estudo de caso 3 a rede fosse avaliada plenamente (mesmo arbitrando o diâmetro mínimo de 150 mm), seriam 623, ou seja, 789.730.223.053.603.000 de soluções, o que tornaria inviável computacionalmente tal procedimento ser realizado em um computador comum. Caso tal busca fosse efetuada, esta demanda ultrapassaria centenas de anos.

O dimensionamento hidráulico de redes coletoras de esgoto é demasiadamente restritivo, o que levou ao estudo de um modelo que não utilizasse técnicas de otimização que utilizassem penalidades ou não obtivessem resultados comprovados ou amplamente detalhados para esta situação. Em todos os casos, ficou demonstrada a eficácia do modelo de busca completa para o dimensionamento ótimo de redes coletoras de esgoto.

Um resumo dos valores e percentuais reduzidos pela FARC está exibido na tabela 15 e figura 9 . Na tabela 16 percebem-se as diferentes estratégias utilizadas pelo algoritmo e suas respectivas consequências econômicas.

\begin{tabular}{c|c|c|c}
\hline Descrição & $\begin{array}{c}\text { Valor sem a aplicação } \\
\text { do modelo (R\$) }\end{array}$ & $\begin{array}{c}\text { Valor com a aplicação } \\
\text { do modelo (R\$) }\end{array}$ & $\begin{array}{c}\text { Percentual de redução } \\
\text { em relação à solução } \\
\text { inicial (\%) }\end{array}$ \\
\hline Rede Real 1 (sub-bacia 1) & $70.751,09$ & $61.316,44$ & $15,39 \%$ \\
\hline Rede Real 2 (sub-bacia 1) & $50.390,54$ & $49.303,76$ & $2,20 \%$ \\
\hline Rede Real 2 (sub-bacia 3) & $40.200,04$ & $38.254,12$ & $5,09 \%$ \\
\hline
\end{tabular}

Tabela 15: Valores e percentuais de redução obtidos para os estudos de caso 


\section{Artigo Técnico}

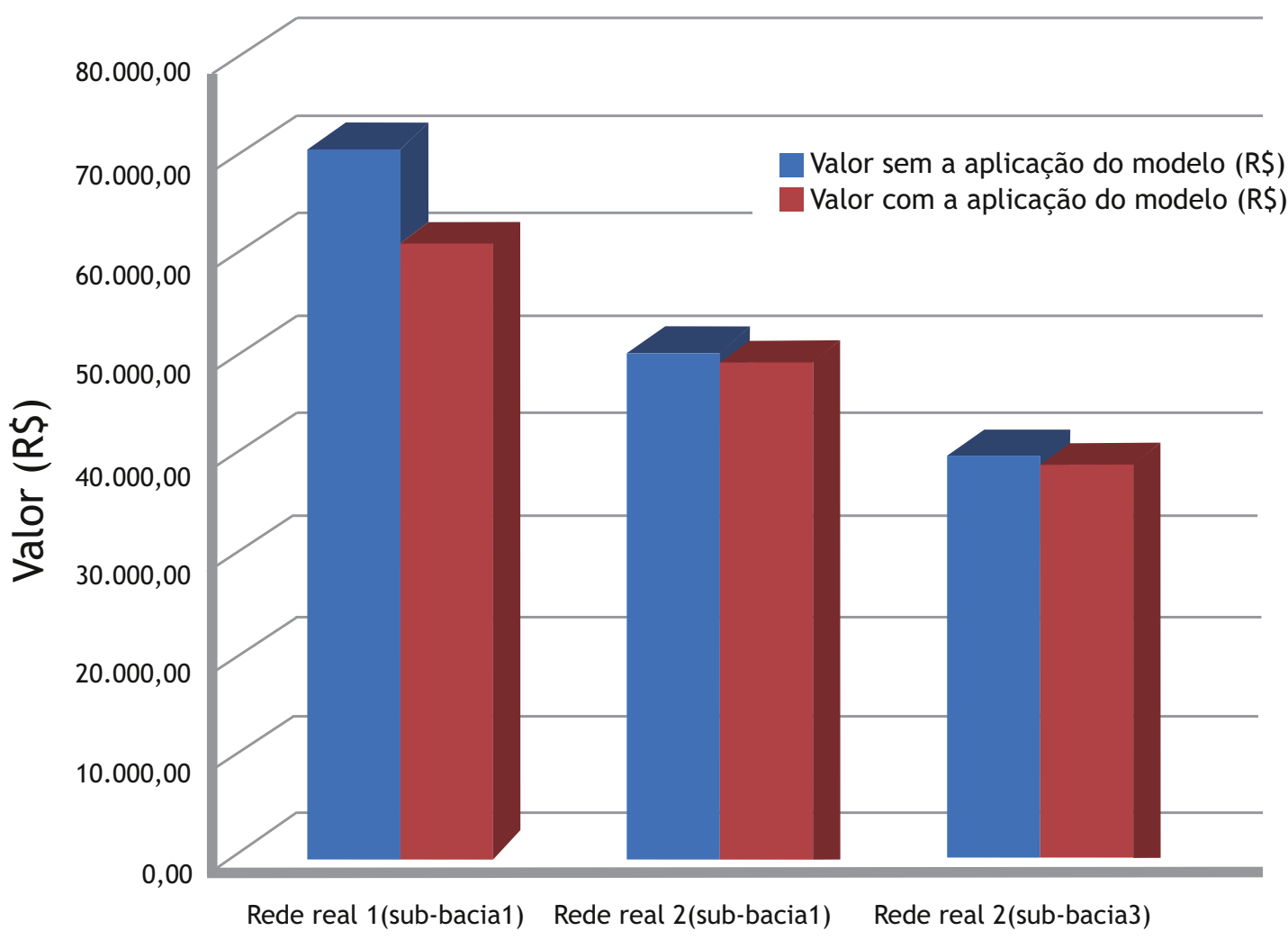

Figura 9: Valores obtidos para os dois estudos de caso

\begin{tabular}{|c|c|c|}
\hline Descrição & Estratégia adotada & Consequências econômicas \\
\hline Rede Real 1 (sub-bacia 1) & $\begin{array}{l}\text { Aumento dos diâmetros dos } \\
\text { trechos }(1-6) \text { e (1-7) de } 150 \text { para } \\
200 \mathrm{~mm} \text { (coletores finais da rede) }\end{array}$ & $\begin{array}{l}\text { Eliminação do volume de } \\
\text { escavações em profundidades } \\
\text { superiores a } 4 \text { metros e redução } \\
\text { do volume de escavação em } \\
\text { profundidades inferiores a } 2 \\
\text { metros e área de escoramento }\end{array}$ \\
\hline Rede Real 2 (sub-bacia 1) & $\begin{array}{l}\text { Redução do diâmetro do ultimo } \\
\text { trecho da rede (1-6) de } 300 \text { para } \\
250 \mathrm{~mm}\end{array}$ & $\begin{array}{l}\text { Aumento suave dos custos com } \\
\text { escavação e escoramento. } \\
\text { Redução dos valores com o } \\
\text { assentamento e aquisição das } \\
\text { tubulações }\end{array}$ \\
\hline Rede Real 2 (sub-bacia 3) & $\begin{array}{l}\text { Redução do diâmetro do ultimo } \\
\text { trecho da rede (3-4) de } 300 \text { para } \\
250 \mathrm{~mm}\end{array}$ & $\begin{array}{l}\text { Aumento suave dos custos com } \\
\text { escavação e escoramento. } \\
\text { Redução dos valores com o } \\
\text { assentamento e aquisição das } \\
\text { tubulações }\end{array}$ \\
\hline
\end{tabular}

Tabela 16: Estratégias adotadas pelo modelo e suas respectivas consequências econômicas para os dois estudos de caso 


\section{Conclusões e recomendações}

Em princípio, deparou-se que redes superiores a nove trechos exigiriam uma alta velocidade computacional pelo fato de o algoritmo primeiramente percorrer todas as soluções possíveis. Como solução, dividiram-se as redes reais em sub-bacias, o que não compromete os resultados finais, pois o coletor tronco foi dimensionado a partir dos resultados das sub-bacias contribuintes. Com tal implicação, as duas redes foram dimensionadas no UFC9 e, em seguida, foi utilizada a ferramenta computacional e analisada sua eficácia.

A formulação do problema de redução de custos deste trabalho caracteriza-se por possuir apenas um objetivo: atenuar os custos com a implantação de redes coletoras de esgotos tendo em vista sua topografia e outros parâmetros pertinentes.

Pode-se afirmar, de acordo com as comparações realizadas, que os resultados dos dois cenários apresentados comprovam a eficácia do modelo, haja vista que houve redução de custos nos dois estudos de caso e, ainda, com o emprego de diferentes estratégias para culminar no objetivo final.

Um ponto que se deve frisar em relação à pesquisa foi agregar redes reais, como prova da viabilidade técnica resultante do modelo. Vale ressaltar que mesmo com um maior tempo que uma rede de grande porte pode acarretar com a utilização da ferramenta computacional, tal procedimento ainda é valido, pois se tem a garantia da solução ótima global do sistema em questão. Ademais, pode-se trabalhar (a partir da modificação do código fonte) com diversos computadores concomitantemente.

Em suma, além de atualmente nenhum programa atingir objetivos similares em escala real, a racionalização de cálculos e custos presentes nos modelos deste trabalho faz com que a ferramenta seja prática e útil.

Embora o modelo possua todas as características para a redução de custos em uma rede coletora de esgotos, algumas sugestões relevantes com o intuito de expandir a aplicabilidade e o conhecimento do trabalho desenvolvido:

- Possibilidade de inserção de outros materiais de tubulação além do PVC.

- Possibilidade de inserção de diâmetros, fora da gama comercial atualmente disponível.

- Implantação de uma programação com processo paralelo, para que diversas instruções sejam processadas simultaneamente.

- Atualização automática dos preços via internet;

\section{Referências}

ABNT - Associação Brasileira de Normas Técnicas - NBR-9649 - Projeto de redes coletoras de esgoto sanitário - Procedimento. Rio de Janeiro: ABNT, 1986.

ARGAMAN, Y.; SHAMIR, U.; SPIVAK, E. Design of optimal sewerage systems. Journal of the Environmental Engineering Division, ASCE, v.99, n.5, p.703-716, Out., 1973.

BRASIL. Programa de Modernização do Setor Saneamento (Brasil). Instituto de Pesquisa Econômica Aplicada. SNIS - Sistema Nacional de Informações Sobre Saneamento. Visão Geral da Prestação dos Serviços de Água e Esgotos - 2002: (Um Extrato do Diagnóstico dos Serviços de Água e Esgotos). BRASÍLIA: PMSS/SNIS, 2004. 93 p.

CYNAMON, S. E. Sistema não convencional de esgoto sanitário a custo reduzido. $2^{\mathrm{a}}$. ed. Rio de Janeiro: Escola Nacional de Saúde Publica, 1986. $52 \mathrm{p}$.

MAGALHÃES, C. A. G. Dimensionamento dos sistemas de esgotos sanitários de grande porte via redução de custos. Dissertação (Mestrado) - Escola de Engenharia de São Carlos, Universidade de São Paulo. São Carlos, 1995. 195p.

RODRIGUES, G. P. W. Computação gráfica e modelagem computacional aplicadas ao traçado e dimensionamento hidráulico de redes coletoras de esgoto sanitário. Dissertação de mestrado - Universidade Federal do Ceará, 2006. 165 p. 